\title{
Lesion of the Cervix Uteri
}

National Cancer Institute

\section{Source}

National Cancer Institute. Lesion of the Cervix Uteri. NCI Thesaurus. Code C155726.

A localized pathological or traumatic structural change, damage, deformity, or discontinuity of the cervix uteri. 